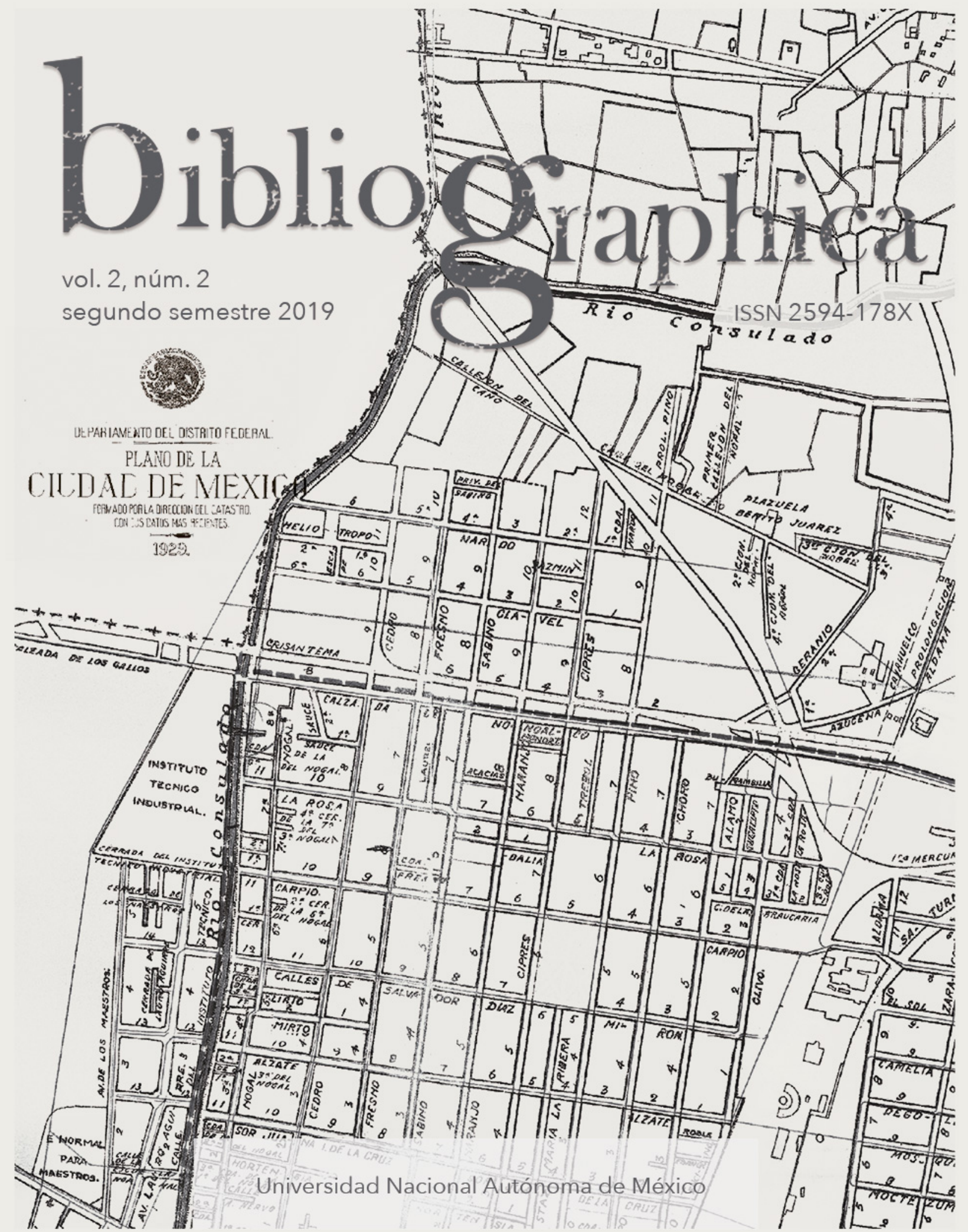




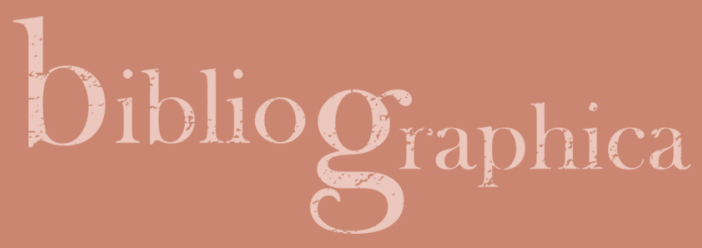

\section{Descripción de un libro del siglo XVI que formó parte del acervo original del Colegio de la Compañía de Jesús de Pátzcuaro}

Description of a $16^{\text {th }}$ Century Book that Belonged to the Original Collection of the Library of the Colegio de la Compañía de Jesús of Pátzcuaro

\section{Roberto Aceves Ávila}

racevesa@hotmail.com

Becario del Programa de Estancias Posdoctorales de Conacyt

Centro Universitario de Ciencias Sociales y Humanidades

Universidad de Guadalajara

Recepción: 20.05.2019 / Aceptación: 24.06.2019

DOI: https://doi.org/10.22201/iib.bibliographica.2019.2.50 
Resumen Artículo que describe un libro del teólogo jesuita español Francisco de Ribera sobre los comentarios a los 12 profetas menores del Antiguo Testamento, impreso en Salamanca, España, en 1587. Es uno de los ejemplares más antiguos perteneciente a la biblioteca del Colegio de la Compañía de Jesús de Pátzcuaro, en Michoacán, y hasta ahora no había sido registrado. Este trabajo se inserta en una investigación más amplia sobre impresos religiosos y cultura escrita en México. La descripción y el análisis de su importancia en el contexto de una biblioteca de la época es una aportación al conocimiento del patrimonio bibliográfico del país y contribuye a la mejor comprensión de la historia cultural mexicana durante el siglo XVI.

Palabras clave

Colegio de la Compañía de Jesús de Pátzcuaro; Francisco de Ribera; jesuitas; bibliotecas religiosas en el siglo XVI; comentarios a los 12 profetas menores.

Abstract This article describes a book by the Spanish Jesuit theologian Francisco de Ribera, about the commentaries to the Old Testament's 12 Minor Prophets, printed in Salamanca, Spain, in 1587. It is one of the oldest books in the collection of the Colegio de la Compañía de Jesús of Pátzcuaro, in Michoacán, which had not been identified until recently. This work is part of a broader research on Mexican religious prints and written culture. Its description and the analysis of its importance, in the context of a library of its time, are a contribution to the study of the country's bibliographic heritage and to a deeper understanding of the cultural history of Mexico during the $16^{\text {th }}$ of Century.

Keywords Colegio de la Compañía de Jesús of Pátzcuaro; Francisco de Ribera; Jesuits; religious libraries in $16^{\text {th }}$ Century Mexico; commentaries on the 12 Minor Prophets. 


\section{Introducción}

Una de las actividades fundamentales en la investigación histórica es la búsqueda de fuentes documentales que apoyen la labor del historiador. Sin embargo, no basta el descubrimiento de nuevas fuentes, también es necesario darlas a conocer y difundir su conocimiento entre la comunidad de académicos, utilizando para ello metodologías adecuadas de descripción y clasificación que permitan a los interesados su uso y acceso.

Por otra parte, en el caso de los libros, estudiar las cuestiones relativas a su producción, circulación y apropiación es una línea de investigación historiográfica que permite conocer el ambiente intelectual que los rodeó, el imaginario y mentalidades de los lectores a partir de su relación con la cultura escrita, al igual que otras cuestiones relativas a la historia social de las comunidades receptoras. Señalan Roger Chartier y Guglielmo Cavallo que el estudio de un libro no radica únicamente en su importancia como objeto impreso, debe reconocerse que "un texto no existe más que porque existe un lector para conferirle significado"." En la medida en que se logren completar los acervos pertenecientes a diferentes personajes e instituciones, podremos comprender mejor el papel de los libros en la conformación de los imaginarios y mentalidades vinculados con su entorno.

En México, el estudio de la cultura impresa del periodo colonial se encuentra todavía en etapas tempranas. Dentro de este universo de estudio, como bien lo señala Idalia García Aguilar: "la historia de las bibliotecas de la Nueva España, tanto aquellas que fueron de particulares como las que fundaron y conformaron todas las órdenes religiosas, es una historia dispersa, inconclusa, desconocida y, por lo tanto, sujeta a múltiples mitificaciones". ${ }^{2}$ Tan es así que la aportación de un libro a un inventario puede proporcionar nuevas pistas sobre la forma en que la gente interpretaba su entorno cultural particular. Por ello cada nueva pieza, libro o indicio que se aporta a este rompecabezas contribuye a un mejor conocimiento de la realidad de la época. Al respecto, Carlo Ginzburg afirma: "si la realidad es impenetrable, existen zonas privilegiadas -pruebas, indicios- que permiten descifrarla [...] Minúsculas singularidades paleográficas han sido usadas como rastros que permitían reconstruir

\footnotetext{
${ }^{1}$ Guglielmo Cavallo y Roger Chartier, coords., Historia de la lectura en el mundo occidental (Madrid: Taurus, 1998), 11.

${ }^{2}$ Idalia García Aguilar, "Entre el olvido y la supervivencia: los libros jesuitas del Colegio de San Luis Potosí", Revista de El Colegio de San Luis 6, núm. 11 (enero-junio de 2016): 48.
} 
intercambios y transformaciones culturales", y por ello "ciertos mínimos indicios han sido asumidos una y otra vez como ejemplos reveladores de fenómenos más generales: la visión del mundo de una cierta clase social, o de un escritor, o de una sociedad entera". ${ }^{3}$ Debido a ello en este trabajo presentamos un ejemplar que localizamos a lo largo de nuestras labores de investigación sobre impresos religiosos y cultura escrita en México. ${ }^{4}$ Se trata de un libro del teólogo jesuita Francisco de Ribera, impreso en Salamanca en 1587, que es uno de los más antiguos perteneciente al Colegio de la Compañía de Jesús de Pátzcuaro, y que hasta ahora no había sido identificado como parte de su biblioteca. Su descripción y difusión representa una aportación al patrimonio bibliográfico de México y busca contribuir al conocimiento de la historia cultural mexicana en el siglo XVI.

\section{El inventario bibliográfico del Colegio de la Compañía de Jesús de Pátzcuaro}

En el año 2002, el investigador Gabriel Silva Mandujano -del Instituto de Investigaciones Históricas de la Universidad Michoacana de San Nicolás de Hidalgo- publicó un artículo donde detallaba la identificación y descripción de 11 obras en 12 libros que pertenecieron al acervo del Colegio de la Compañía de Jesús de Pátzcuaro, los cuales van desde 1584 hasta 1728 y se localizan en la Biblioteca Pública Universitaria de Michoacán. ${ }^{5}$ La identificación fue posible gracias a que todos los ejemplares cuentan con la anotación manuscrita "Del Colegio de la Compañía de Pazcuaro" y una marca de fuego que "consiste en una rueda con cuchillas, un látigo y una pértiga, instrumentos del martirio de

${ }^{3}$ Carlo Ginzburg, Mitos, emblemas, indicios. Morfología e historia (Barcelona: Gedisa, 2008), 219.

${ }^{4}$ Como becario del Programa de Estancias Posdoctorales nacionales del Conacyt (20172019), adscrito a la Universidad de Guadalajara, con la dirección de proyecto del doctor José Refugio de la Torre Curiel.

${ }^{5}$ Gabriel Silva Mandujano, "Colegio de la Compañía de Jesús de Pátzcuaro", en Nuestros libros. Encanto de lo antiguo, coord. de Juan García Tapia (Morelia: Universidad Michoacana de San Nicolás de Hidalgo, 2002), 266-274. 
santa Catalina de Alejandría, titular del colegio". ${ }^{\prime 6}$ Como veremos, el ejemplar que localizamos también comparte estas características.

La lista cronológicamente ordenada de los libros identificados por Silva Mandujano es la siguiente: ${ }^{7}$

1. San Jerónimo, Opera omnia. París: Sebastián Nivelio, 1579.

2. Graciano, Liber sextus decretalium. Lyon: [s. i.], 1584.

3. Luis de Molina, De lustitia, tomus primus. Cuenca: Juan Masselini, tipógrafo, 1593.

4. Luis de Molina, De lustitia, tomus secundus. Cuenca: Miguel Serrano de Vargas, 1597.

5. Francisco Suárez, Metaphysicarum disputationes. Salamanca: Juan y Andrés Renault Hermanos, 1597.

6. Juan Lorini, Commentaria in Psalmos usque ad quinquagesimum. Lyon: [s. i.], 1611.

7. Francisco Lucas, Concordantiae Bibliorum utriusque Testamenti Veteris et Novi. Roma: Mateo Berjon, 1620.

${ }^{6}$ Ibid. Debe recordarse que a santa Catalina, si bien su leyenda no cuenta con fundamentos históricos, se le consideraba "una bellísima e inteligente mujer de dieciocho años que, a través de estudios profundos, conoció el cristianismo y se convirtió". Durante la persecución de Majencio, el emperador la puso a discutir con 50 filósofos para tratar de convencerla de renunciar a su fe, pero ella acabó convirtiendo a varios de ellos con sus argumentos. Por ello, Majencio la martirizó despedazándola con la rueda dentada, y posteriormente los ángeles llevaron su cuerpo al Sinaí, donde fue construido el célebre monasterio que hoy lleva su nombre. Se le considera patrona de filósofos, teólogos y estudiantes. Véase Héctor H. Schenone, Iconografía del arte colonial. Los santos. Vol. I (Buenos Aires: Fundación Tarea, 1992), 208-211.

7 García Aguilar identifica la existencia de una memoria documental de la "Librería del Colegio de Pátzcuaro" en el Archivo Histórico Nacional de España (AHN, Clero, Jesuitas, L. 87), la cual no hemos podido consultar. También señala, como origen de ésta y otras memorias similares, que en abril y julio de 1767 se expidieron cédulas reales que establecieron procedimientos para realizar el registro de lo que existía en los aposentos y casas comunes de los jesuitas, lo cual permitió generar inventarios detallados de los libros y manuscritos en poder de los miembros de la orden al momento de su expulsión. Véase "Imprenta y librerías jesuitas en Nueva España", en El libro en circulación en la América colonial. Producción, circuitos de distribución y conformación de bibliotecas en los siglos XVI al XVIII, coord. de Idalia García Aguilar y Pedro Rueda Ramírez (México: Quivira, 2014), 205-237. Está entonces por hacerse la confrontación entre esta lista elaborada por Silva Mandujano y la de los libros contenidos en dicha biblioteca hasta 1767, identificada por García Aguilar. 
8. Carta del rey de Francia al cardenal de Etre, memorial de las razones que lo obligan a tomar las armas y auto de apelación del mesmo christianissimo al futuro concilio. Barcelona: Rafael Ficaeri, 1688.

9. Biblia Sacra Vulgata editionis. Lyon: Bartolomé Martín, 1692.

10. Roberto Belarmino, Variorum operum. Venecia: Juan Malaquino, 1721.

11. Roberto Belarmino, Descriptoribus ecclesiaticis liber unus. Venecia: Cristóbal Zane, 1728.

12. Antonino Diana, Opera Omniae. Venecia: Nicolás Pezzana, 1728.

Como observamos a primera vista, en esta biblioteca -compuesta en su mayoría por libros en latín- predominan los teólogos jesuitas de primera línea (Molina, Suárez, Belarmino, Lorini) con obras destinadas a la formación de los colegiales jesuitas en materias de filosofía, derecho, teología moral y exégesis de la Biblia. Destacan un ejemplar de la Vulgata, edición canónica para la Iglesia católica a partir del Concilio de Trento, así como las obras completas de san Jerónimo, quien fue el encargado de preparar dicha traducción del texto bíblico al latín, a partir de los originales hebreos y griegos, a finales del siglo IV.

\section{El Colegio de la Compañía de Pátzcuaro: fundación, dispersión y el hallazgo de un libro de su biblioteca}

Antes de describir el libro de Francisco de Ribera perteneciente a este acervo, es necesario hacer una breve historia del colegio jesuita de Pátzcuaro. ${ }^{8}$ Fue el obispo Vasco de Quiroga quien solicitó por primera vez la presencia de los jesuitas allí durante su visita a España entre 1547 a 1553. Los primeros jesuitas llegaron a Pátzcuaro en 1574, después de la muerte de Quiroga, y en 1576 -gracias a la intervención del padre provincial Pedro Sánchez-ya contaban con residencia y autorización para establecer sus colegios. Justino Fernández destaca que se escogió como sitio para fundarlos el lugar que había ocupado el templo mayor

\footnotetext{
${ }^{8}$ Para los jesuitas, un colegio era una institución educativa en la que vivían los educandos, y donde además de instruir a los jóvenes "en letras y buenas costumbres", se les evaluaba y en su caso se les recibía, ya fuese como candidatos para proseguir su preparación en calidad de miembros de la Compañía, o bien como "operarios fieles que con ejemplo y doctrina procuren reducir al gremio de la Santa Madre Iglesia aquellas sus naciones" de donde proviniesen. Véase Ignacio de Loyola, Obras completas, 3a. ed. revisada (Madrid: Biblioteca de Autores Cristianos, 1977), 517, 889.
} 
purépecha y que uno de los alumnos más distinguidos fue don Pedro Caltzonzi, nieto del último rey de dicha etnia. ${ }^{9}$

En el siglo XVIII mantenían dos colegios: el Seminario Real de Santa Catalina y el Colegio de San Ignacio para los estudios de filosofía y teología moral. ${ }^{10}$ Los jesuitas permanecieron allí hasta 1767, año en el que Carlos III ordenó su expulsión. Fernández agrega que después de este acontecimiento las instalaciones siguieron funcionando como escuela primaria hasta 1854, cuando se hicieron cargo de ellas los padres paulinos. En 1858 el gobierno del Estado las clausuró y se restablecieron con el carácter de Seminario auxiliar del Tridentino de Michoacán. Por su parte, Francisco Fernández de Córdoba señala que, a raíz de la expulsión de 1767, la biblioteca comenzó a dispersarse, ${ }^{11}$ pero se conservaron algunos ejemplares hasta principios del siglo XX, sin embargo la Revolución mexicana acabó por desaparecerla. ${ }^{12}$ En 1912 las instalaciones del Seminario auxiliar fueron clausuradas y el edificio se convirtió en escuela primaria particular, posteriormente fue cuartel hasta 1930, y más tarde escuela oficial del Estado. ${ }^{13}$

Como evidencia de la dispersión de esta biblioteca, recuerdo que a principios de los años 90 del siglo XX -en la librería de ocasión de don Ubaldo López, en la colonia Doctores de la Ciudad de México- ${ }^{14}$ revisé una pila de libros y

9 Justino Fernández, Pátzcuaro. Su situación, historia y características (México: Talleres de Impresión de Estampillas y Valores, 1936), 43.

10 Silva Mandujano, "Colegio de la Compañía de Jesús de Pátzcuaro", 267.

${ }^{11}$ Esta dispersión arranca con la disposición firmada por Carlos III el 17 de diciembre de 1770, que establecía "un Reglamento que prescribía que los fondos jesuíticos no fuesen vendidos sino entregados a los prelados y sucesores para el aprovechamiento público de sus diocesanos. Acuerdo que, el 4 de enero de 1771, se remitía al conde de Aranda, Presidente del Consejo, para que procediera a su rápida ejecución". Véase Javier Vergara Ciordia, "El proceso de expropiación de la biblioteca de los jesuitas en Pamplona (17671774)", Revista de Historia Moderna, núm. 26 (2008): 328, acceso el 20 de mayo de 2019, http://dx.doi.org/10.14198/RHM2008.26.11.

12 Francisco Fernández de Córdova, "Sumaria relación de las bibliotecas de Michoacán", Historia Mexicana 3, núm. 1 (julio-septiembre de 1953): 135, acceso el 20 de mayo de 2019, https://historiamexicana.colmex.mx/index.php/RHM/issue/view/48.

${ }^{13}$ Fernández, Pátzcuaro. Su situación, historia y características, 43-44.

${ }_{14}$ Ubaldo López Barrientos, padre y abuelo de, al menos, dos generaciones de libreros de viejo (o de ocasión, como ahora muchos prefieren que se les llame, y que mantienen varios de sus establecimientos en la calle Donceles en la Ciudad de México), fue padre del investigador y librero Mercurio López Casillas, especialista en la obra de José Guadalupe Posada. Comenzó don Ubaldo vendiendo libros en la Lagunilla y terminó sus días de librero en un local de la calle Claude Bernard, en la colonia Doctores. Fue famoso por su 
papeles destinados a la basura. Al observar con cuidado detecté un ejemplar en folio muy maltratado, con daños por bibliófagos, el lomo destruido y pésimamente "restaurado" con tela encolada, pero con restos de una magnífica encuadernación renacentista.

Cuál no sería mi sorpresa al comprobar que era un ejemplar elaborado en Salamanca en 1587 en la imprenta del flamenco Guillermo Foquel. ${ }^{15}$ Se trataba de la obra Librum doudecim Prophetarum comentarii o Libro de los comentarios sobre los doce profetas bíblicos ${ }^{16}$ del teólogo jesuita Francisco de Ribera (15361591), quien fue rector de la Universidad de Salamanca en 1567, desempeñó la cátedra de Escritura durante 16 años (1575-1591) en la misma institución y además fue el confesor y primer biógrafo de santa Teresa de Jesús. ${ }^{17}$

El libro presentaba dos marcas de fuego en los cantos y una anotación manuscrita en letra cursiva al pie de la portada, que despertaron mi interés. La anotación dice: "del Collegio dela comp de Jesus de Pazcuaro-". Don Ubaldo no recordaba cómo había llegado dicho ejemplar a su poder. El libro estaba a punto de ser desechado, dado su mal estado de conservación y el poco interés que despertaba en muchos compradores, debido a que trataba sobre temas religiosos y estaba escrito en latín. Después de examinarlo, don Ubaldo accedió a vendérmelo en 500 pesos y desde entonces está disponible para su consulta en mi biblioteca personal. ${ }^{18}$

clientela, formada por bibliófilos como Guillermo Tovar y de Teresa y Carlos Monsiváis. A la muerte de don Ubaldo a finales de los años 90, su librería cerró y su inventario pasó a poder de sus hijos.

15 Para noticias sobre este impresor véase Leonor Zozaya-Montes, "Algunas aclaraciones sobre Guillermo Foquel, un impresor del siglo XVI", Torre de los Lujanes 43 (2001): 189203, acceso el 20 de mayo de 2019, http://digital.csic.es/handle/10261/29822.

${ }^{16}$ El término "doce profetas" se refiere a los libros de los llamados profetas menores que forman parte de los Profetas, la segunda de las tres principales secciones de la Biblia hebrea, siendo las otras la Torá y las Escrituras. Entre los profetas menores - llamados así no debido a su importancia escrituraria sino por su escasa producción, comparada con la de otros profetas como Ezequiel- se incluye a Oseas, Joel, Amós, Abdías, Jonás, Miqueas Nahum, Habacuc, Sofonías, Ageo, Zacarías y Malaquías.

${ }_{17}$ Para una breve biografía del jesuita Francisco de Ribera, consúltese la elaborada por Javier Burrieza Sánchez en el Diccionario biográfico español de la Real Academia de la Historia; acceso el 20 de mayo de 2019, http://dbe.rah.es/biografias/20974/francisco-de-ribera. ${ }_{18}$ Por anecdóticas o triviales que puedan parecer estas noticias, en realidad cumplen con la función de proporcionar información sobre la procedencia (legal o ilegal) del ejemplar, lo que es fundamental para establecer la historia de todo libro. Al respecto, recuérdese la curiosa historia y controversia sobre cómo el doctor Nicolás León encontró en el convento franciscano de Celaya una copia del manuscrito original del Libro segun- 


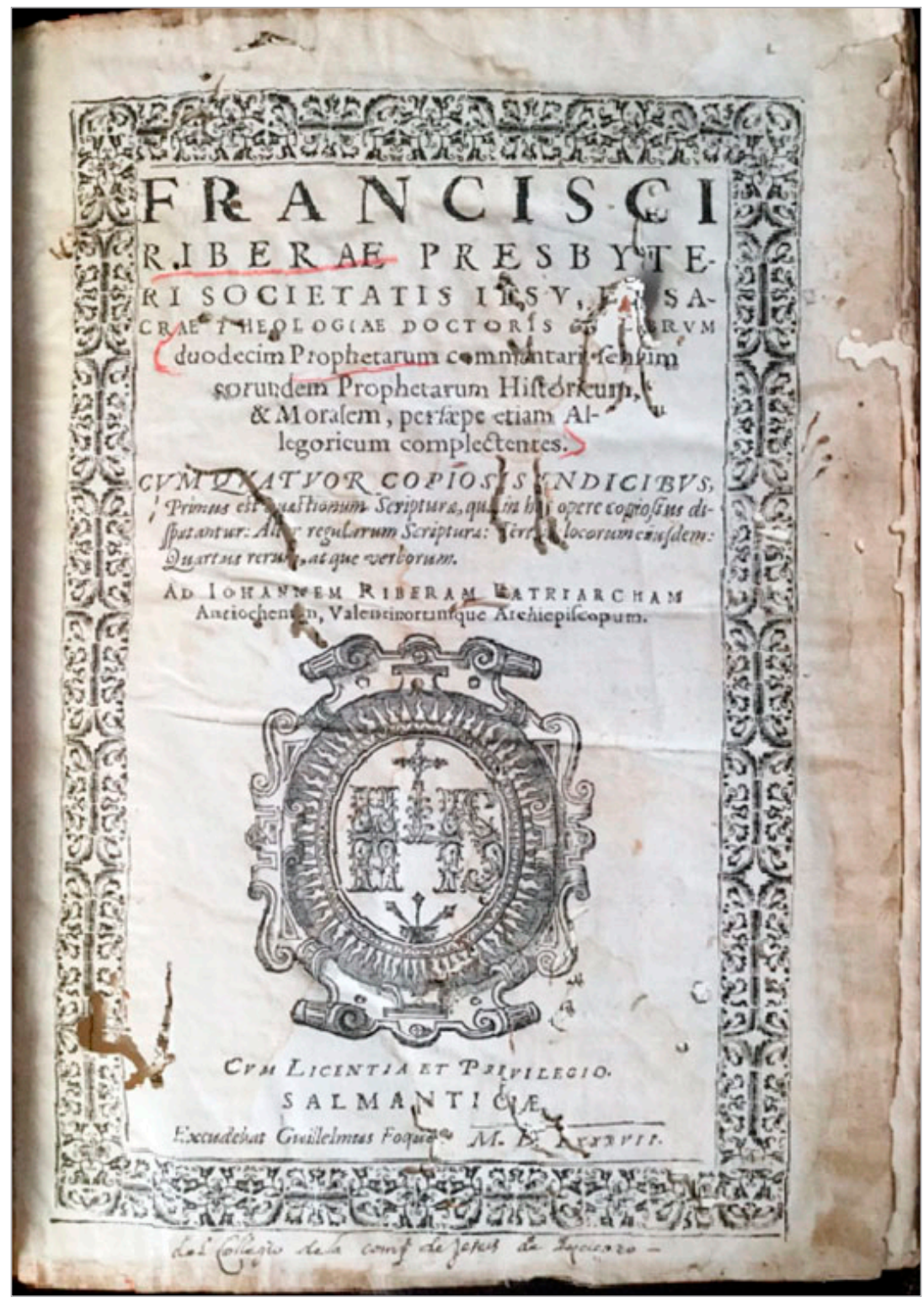

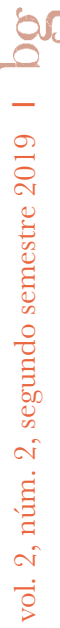

Figura 1. Portada del Librum doudecim Prophetarum comentarii (1587).

Fotografía del autor. 


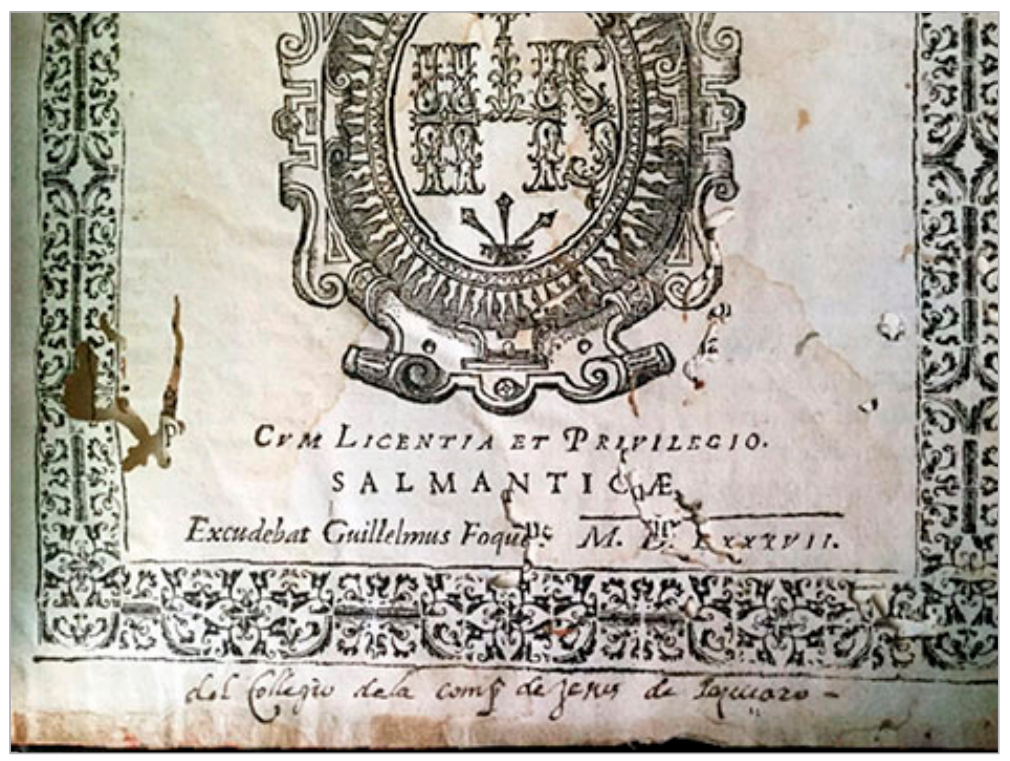

Figura 2. Detalle en portada de la marca manuscrita de procedencia.

Fotografía del autor.

do de la Crónica Miscelánea de fray Antonio Tello, que posteriormente acabó vendiendo a la biblioteca John Carter Brown en Providence, Rhode Island, Estados Unidos. En la introducción a la primera edición impresa de la obra de Tello (Guadalajara: Imprenta de la República Literaria, 1891), III-IV, José López Portillo y Rojas relata cómo el descubrimiento de este manuscrito por parte de León "parece fábula: [lo halló] en la tienda de un especiero que la había comprado por peso de papel para envolver con ella ventas al menudeo. Cincuenta pesos costóle el rescate de tan valioso documento, y eso debido a la sospecha de su importancia que se desató en el tendero, a la vista del entusiasmo del bibliófilo". Años más tarde fray Luis del Refugio de Palacio Basave, erudito aunque farragoso comentador de Tello, ponía en duda dicha versión, señalando que -con diversos trucos- a León le permitieron los franciscanos de Celaya revisar su biblioteca conventual. Palacio señala que: "penetra el expertísimo Dr. León a nuestra florida biblioteca de Celaya; los libros de traza vieja, a que su olfato o instinto lo acercaba, comprimidos de un ángulo hacía deslizar por sus dedos todo el monto del follaje, y así se hacía cargo. Escogido esto y aquello, [...] paró en sus manos el manuscrito original de nuestro venerable padre Fray Antonio Tello, [...] y adiós y buenas noches... urdióse la tramoya de los alcatraces para especies y así bien condimentada, pero dura aun de tragar, salió en los moldes de la prensa la guisada patraña del hallazgo. ¿Dónde te lo jurta-jallaste? preguntan por Michoacán los indios para bocadillo de los crédulos" (citado por José Cornejo Franco en su introducción al tomo III de la crónica de Tello (Guadalajara: Editorial Font, 1942), XIV-XV. 
Elementos para la descripción bibliográfica del Librum doudecim Prophetarum comentarii, del jesuita Francisco de Ribera

Como lo señala Carmen Castañeda, Roger Chartier ha puesto a la historia y producción del libro en el centro de una historia de las prácticas, ya que éstas y sus representaciones estructuran el mundo social. ${ }^{19}$ La descripción precisa del libro antiguo es fundamental no sólo para su identificación, sino también para dar cuenta de algunos detalles relacionados con su producción, apropiación y distribución, entre otros, que nos permiten identificar redes culturales y otros elementos de la cultura escrita.

Existen varias formas de describir y catalogar el libro impreso. En este caso utilizaremos como base para nuestra descripción la ficha propuesta por Idalia García Aguilar, ${ }^{20}$ debido a que consideramos que es una de las más completas.

Ribera, Francisco (S. J.) (1537-1591)

FRANCISCI / RIBERAE PRESBITE- / RI SOCIETATIS IESV, E SA- / CRAE THEOLOGIAE DOCTORIS IN LIBRVM / duodecim Prophetarum commentari fenfum / corundem Prophetarum Hiftoricum / \& Moralem, perfaepe etiam Al- / legoricum complectentes. / CVM QVATVOR COPIOSIS INDICIBVS, / Primus est quaestionum Scripturae, qua in hoc opere copiofius di- / fpuntantur: Alior regularum Scrpturae: Tertia locorum eiufdem: / Quarus rerum, atque verborum. / AD IOHANNEM RIBERAM PATRIARCHAM / Antiochenum, Valentinoriumque Archiepifcopum. /

[Grabado con el escudo de la Compañía de Jesús, con el monograma I H S] CVM LICENTIA ET PRIVILEGIO.

SALMANTICAE

Excudebat Guillelmus Foquel. M. D. LXXXVII.

${ }^{19}$ Carmen Castañeda, coord., y Myrna Cortés, colab., Del autor al lector. I. Historia del libro en México (México: CIESAS / Miguel Ángel Porrúa, 2002), 9.

20 Idalia García Aguilar, Secretos del estante: elementos para la descripción bibliográfica del libro antiguo (México: UNAM, 2011), 336, acceso el 20 de mayo de 2019, https://www. academia.edu/4192764/Secretos_del_estante_elementos_para_la_descripci\%C3\%B3n_ del_libro_antiguo. 


\section{Descripción física}

Portada con orla tipográfica.

Dos volúmenes en un mismo tomo con numeración independiente.

[12], 632, 596 p.; Folio, $33.5 \times 23.5 \mathrm{~cm}$.

Texto en latín a dos columnas y enmarcado. Con capitulares iniciales grabadas y decoradas. Apostillas marginales. Orlas al inicio de secciones.

Daños múltiples de polilla y gusano en cubiertas y en muchas partes del texto. Colofón al final del segundo libro: SALMANTICAE / APUD GUILLELMUM FOQUEL. / M. D. LXXXVII

Signaturas: ๆ6, A-Z8, 2A-2O8, 2R4, A-Z8, 2A-2N8, 2O10. ${ }^{21}$

Nuestro ejemplar presenta dos anotaciones manuscritas: la mencionada, al pie de la portada, que representa una marca de propiedad del libro con la leyenda "del Collegio dela comp de Jesus de Pazcuaro-", y una firma: "+ Iñigo de Torres" que aparece al pie del verso de la página \$2, en la que se encuentra la licencia real para la impresión del libro. Esta firma corresponde a la del funcionario que dio fe de dicha licencia, pues aparece en el mismo lugar en otros ejemplares de la misma obra, como puede verse en la reproducción en línea de un volumen de la primera edición de la obra, proveniente de la Universidad Complutense de Madrid. ${ }^{22}$

Esta firma era un elemento legal importante, pues permitía autentificar y controlar el número de ejemplares amparados por el contrato de impresión, evitando con ello fraudes al autor y al fisco. ${ }^{23}$ En la tasa que aparece en los preliminares del libro de Ribera (f. 2v) se señala que la pena por vender un ejem-

${ }^{21}$ La secuencia de las signaturas tipográficas fueron cotejadas con las del ejemplar de la primera edición proveniente de la biblioteca de la Universidad Complutense de Madrid, cuya ficha aparece en el Catálogo Colectivo del Patrimonio Bibliográfico Español (CCPB, núm. de identificación: CСРB000188335-6) para verificar que se correspondiesen, hecho que se corroboró. Consúltese el CCPB, acceso el 20 de mayo de 2019, http://catalogos. mecd.es/CCPB/cgi-ccpb/abnetopac/O12242/ID1c1 ef102/NT2. El ejemplar con el que se hizo el cotejo puede ser consultado en línea, acceso el 4 de julio de 2019, https://babel. hathitrust.org/cgi/pt?id=ucm.5316851323\&view=1 up\&seq=7 o en https://books.google. com.mx/books?id=PjNoNOMqkJIC\&printsec=frontcover\&source=gbs_ge_summary_r\& $\mathrm{cad}=0 \# \mathrm{v}=$ onepage $\& \mathrm{q} \& \mathrm{f}=\mathrm{false}$.

${ }^{22}$ Acceso el 20 de mayo de 2019, https://books.google.com.mx/books?id=PjNoNOMqkJl $C \&$ printsec $=$ frontcover\&source=gbs_ge_summary_r\&cad $=0 \# v=$ onepage\&q\&f=false.

${ }^{23}$ Francisco Javier Lorenzo Pinar, "Contratos de impresión de libros con los tipógrafos extranjeros en Salamanca en el siglo XVI", Documenta e Instrumenta 16 (2018): 107, DOI: http://dx.doi.org/10.5209/rev_DOCU.2018.v16.60230. 
plar no autorizado del libro sería de 50 mil maravedís. La misma tasa indica que el libro se imprimió al costo de "quatro maravedíes y medio cada pliego, y a el dicho precio y no más mandaron que se venda" (f. $2 \mathrm{v}$ ).

Gracias al trabajo de Francisco Javier Lorenzo Pinar, que analiza los contratos de impresión de libros con los impresores salmantinos en el siglo XVI, sabemos que su tiraje fue de mil 500 ejemplares ${ }^{24}$ y que el autor puso especial cuidado en la edición, pues en el contrato con el editor se especificó que la impresión debía hacerse en papel marquilla suministrado por la Compañía de Jesús, "con caracteres bien aderezados [...] y la letra baya llena de tinta", además de que las pruebas serían entregadas diariamente al colegio jesuita donde residía Ribera, quien podría corregirlas por espacio de una hora. ${ }^{25}$

Por otra parte, Antonio Palau y Dulcet, además de la editio princeps de 1587, identificó cinco ediciones más: ${ }^{26}$ la de Roma en 1590, ${ }^{27}$ la de Salamanca de 1598 por loannes Ferdinandus, la de Colonia de 1599 (Coloniae Agrippinae In offic. Birckmannice sumptibus Arnoldi Mylij), ${ }^{28}$ la de Brescia de $1604^{29}$ (Brixiae apud Societatem Brixiensem) y la de París de 1611 (Lutetiae Parisiorum, ex officina typograph. Dionysii Langlaei). ${ }^{30}$ Sin embargo, también existen impresiones de 1593 y 1610, ambas elaboradas en Colonia (Coloniae Agrippinae In offic. Birckmannice, sumptibus Arnoldi Mylij). ${ }^{31}$

\footnotetext{
${ }^{24}$ Ibid., 113.

25 Ibid., 105-106.

${ }^{26}$ Antonio Palau y Dulcet, Manual del librero hispano-americano. Tomo sexto. P-S (Barcelona: Librería Antiquaria, 1927), 274.

${ }^{27}$ Palau y Dulcet no indica el pie de imprenta, pero se trata de la Typographia lacobi Tornerij. Un ejemplar de esta edición, proveniente de la Bayerische StaatsBibliothek digital de Múnich con el número de catálogo 4 Exeg. 716-1 puede consultarse en línea, acceso el 4 de julio de 2019, https://reader.digitale-sammlungen.de/de/fs1/object/display/ bsb10159415_00005.html.

${ }^{28}$ Un ejemplar de esta edición, proveniente de la Bayerische StaatsBibliothek de Múnich con el número de catálogo 6743176 puede consultarse en línea, acceso el 4 de julio de 2019, https://books.google.com.ar/books?id=QwtEAAAAcAAJ\&printsec=frontcover\&hl= es\#v=onepage \&q\&f=false.

29 Palau señala 1605 como año de edición y no incluye el pie de imprenta. Los datos que consignamos provienen de la ficha catalográfica del ejemplar de la Thüringer Universitätsund Landesbibliothek, con número de clasificación 4 Theol.XXIV, 65, acceso el 4 de julio de 2019, https://kataloge.thulb.uni-jena.de.

${ }^{30}$ Palau no indica el pie de imprenta. Datos tomados del catálogo en línea de la Bibliothèque Mazarine de París, acceso el 4 de julio de 2019, https://www.bibliotheque-mazarine. $\mathrm{fr} / \mathrm{en} / \mathrm{catalogues}$.

${ }^{31}$ Ejemplares de estas ediciones, provenientes de la Bayerische StaatsBibliothek de Múnich con los números de catálogo 36016099340012 para el ejemplar de 1593 y 12514627
} 
El ejemplar que describimos presenta dos marcas de fuego en los cantos superior y lateral. En el canto superior aparece la rueda dentada de santa Catalina, marca de propiedad del Colegio de la Compañía de Jesús de Pátzcuaro (Figuras 3 y 4 ).
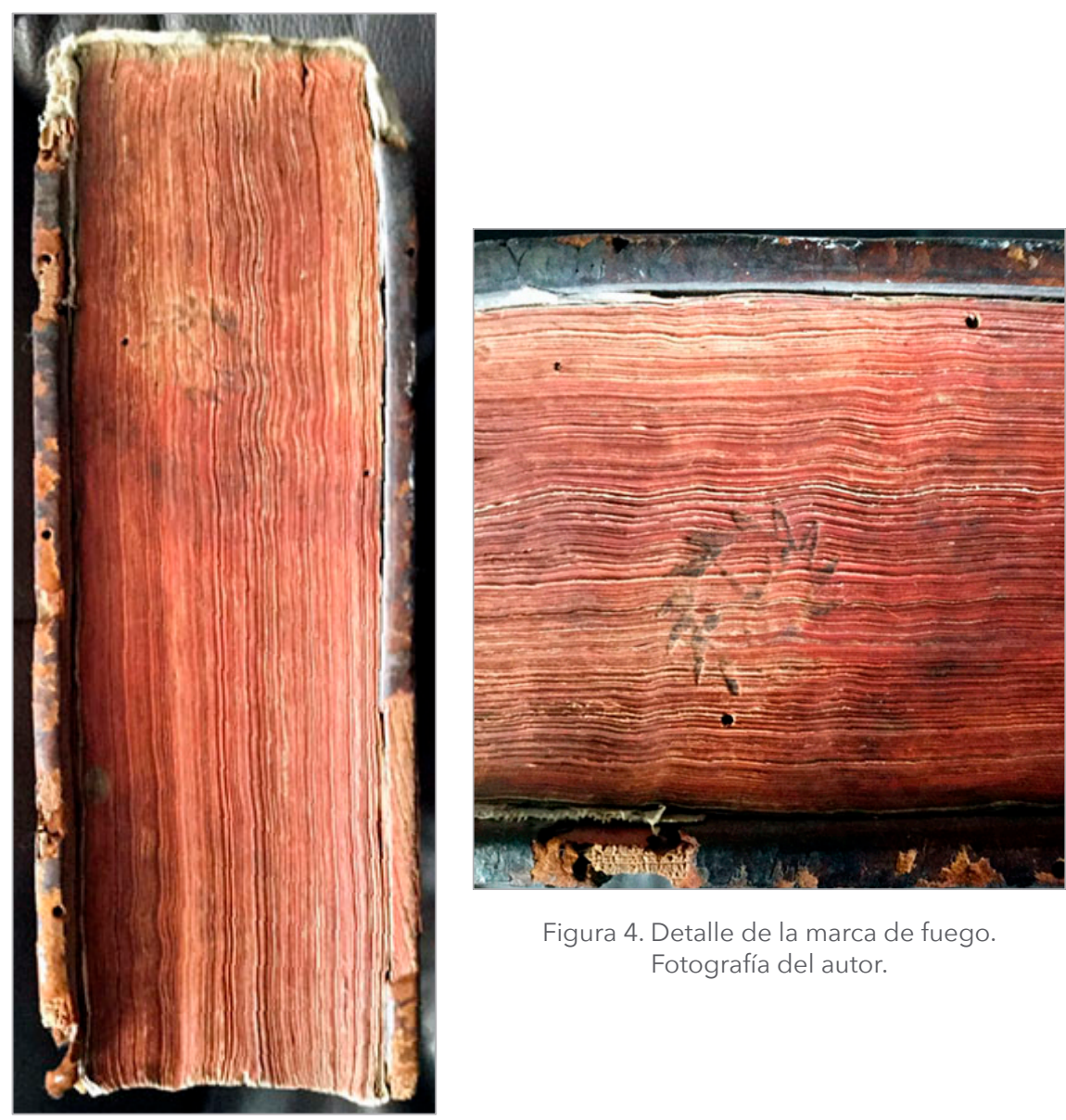

Figura 4. Detalle de la marca de fuego. Fotografía del autor.

Figura 3. Canto superior. Fotografía del autor.

para el de 1610, pueden consultarse respectivamente en línea, acceso el 4 de julio de 2019, https://books.google.com.mx/books?id=dQtEAAAAcAAJ\&printsec=frontcover\&hl $=e s \&$ source $=g b s \_g e \_s u m m a r y \_r \& c a d=0 \# v=$ onepage $\& q \& f=f a l s e$. 
Mientras que en el canto lateral aparecen dos líneas de escritura en las cuales se lee "Riberae / D. Proph.", que hacen referencia al apellido del autor y el título resumido del libro, para identificarlo mejor cuando no se pudiese consultar la información seguramente presente en el lomo del libro (Figuras 5 y 6 ).

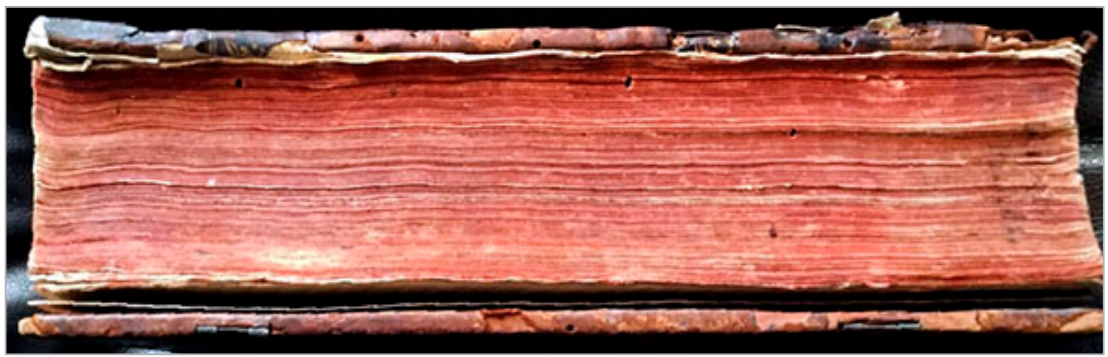

Figura 5. Canto lateral.

Fotografía del autor.

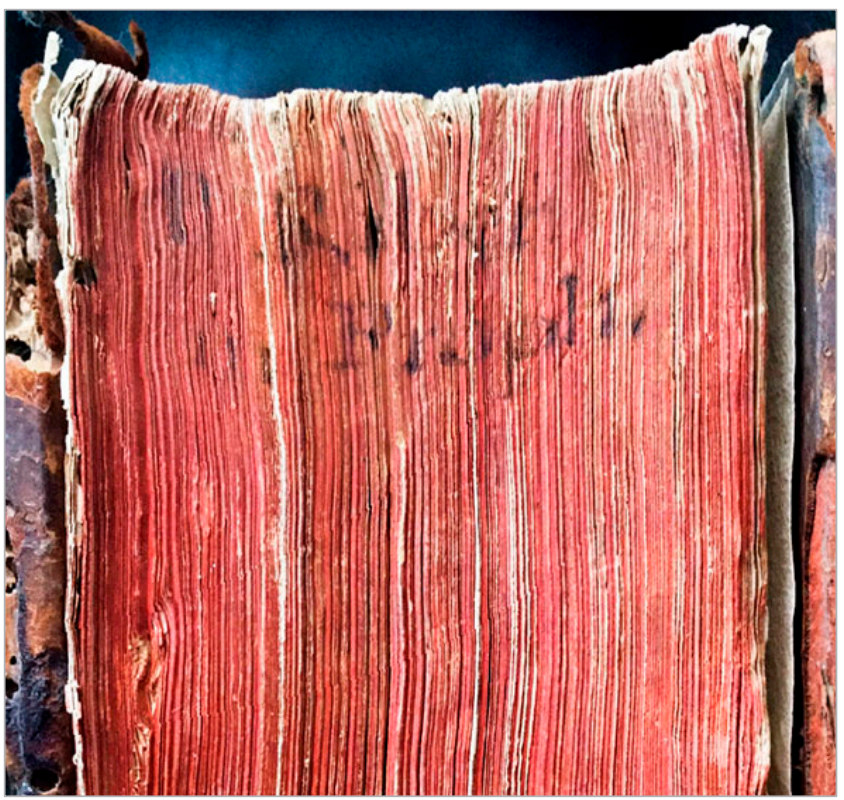

Figura 6. Canto lateral, detalle de la marca de fuego. Fotografía del autor. 
Las cubiertas del volumen son un ejemplo de encuadernación artística elaborada entre los siglos XV y XVI por artesanos españoles. Se trata de una encuadernación renacentista de estilo plateresco, caracterizada por usar como portadas planchas de madera recubiertas de piel de becerro color avellana. Las cubiertas presentan decoración con motivos florales, de caza o figurativos, estampados sobre la piel mediante la técnica del gofrado o estampación en seco. Esta decoración se reparte alrededor de las pastas en orlas rectangulares concéntricas, separadas por entrecalles simples sin decoración. Cada orla decorada presenta un motivo diferente: la exterior es una escena de caza donde aparecen un lebrel, un ciervo, un conejo y un león. La orla intermedia tiene medallones con cabezas de perfil tocadas con corona, casco militar o capelo, y separadas entre sí por elaborados motivos florales. La orla interna muestra figuras de aves entremezcladas con motivos florales. El tablero central, enmarcado por la orla interna, tiene seis florones: tres arriba y tres abajo, dispuestos en arreglo triangular. Al centro aparece un medallón en el cual se representa a la virgen María coronada, vestida con un ropaje amplio, de pie sobre una media luna, sosteniendo al niño Jesús entre sus brazos (Figuras 7 a 9).

En la parte posterior de la encuadernación quedan los restos de dos broches que sirvieron para mantener el libro cerrado, habiéndose perdido los frontales. Prácticamente todo el lomo se destruyó, debido a una intervención muy poco afortunada que simplemente superpuso un pedazo de manta encolada sobre el faltante. Asimismo, trataron de suplirse con trozos de cuero y pegamento diversos faltantes en los bordes de las cubiertas (Figuras 10 y 11).

Tanto las cubiertas como el cuerpo del libro presentan abundantes ataques de bibliófagos (gusanos y polillas), que en algunos casos dificultan la lectura de ciertas páginas y, en el caso de la cubierta frontal, ocasionaron la pérdida de la esquina superior derecha de la encuadernación. A pesar de lo anterior, en general la encuadernación se mantiene firme y el texto es muy claro y bastante legible.

El texto presenta capitulares con motivos florales al comienzo de cada capítulo. Los inicios y finales de los capítulos están adornados con orlas tipográficas de dos tipos: la mayoría ostenta florones dispuestos en arreglos geométricos regulares, mientras que otras muestran escenas, ya sea de ángeles desnudos con ramas en las manos bailando al son de un corno, o figuras antropomórficas entremezcladas con elementos vegetales y acompañadas de lebreles que persiguen a conejos (Figuras 12 a 14). La encuadernación parece indicar que fue elaborada en Salamanca, ya que muchos de los detalles decorativos descritos son iguales a los presentes en encuadernaciones de 
otros libros del siglo XVI conservados en la Biblioteca Histórica de la Universidad de Salamanca. ${ }^{32}$

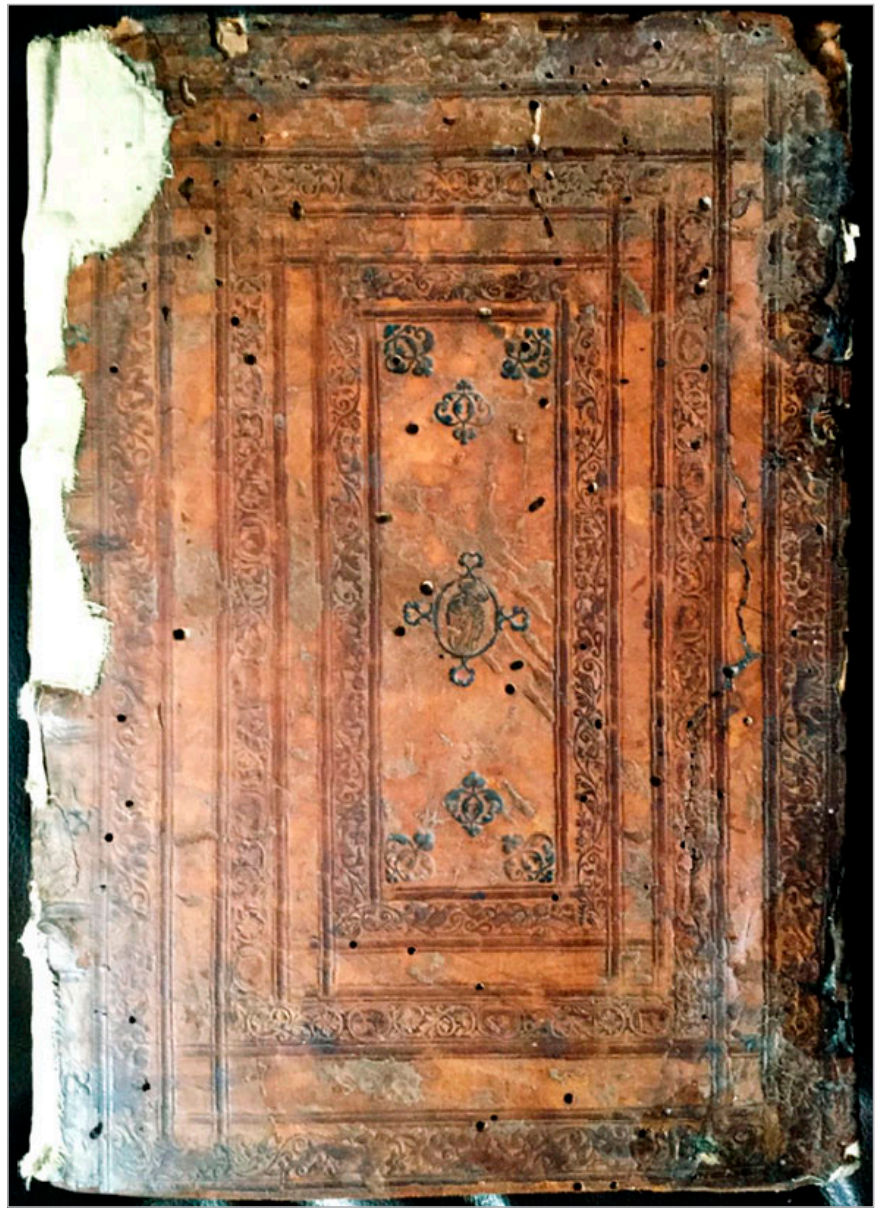

Figura 7. Cubierta anterior del libro de Ribera. Fotografía del autor.

\footnotetext{
32 Véanse ejemplos de estas llamadas ruedas renacentistas decorativas con motivos florales, animales y de trofeos militares, iguales a las descritas, en Elvira Julieta Miguélez González, "El influjo renacentista en las encuadernaciones de la Biblioteca Histórica de la Universidad de Salamanca", Anales de Documentación 12 (2009): 181-208, acceso el 4 de julio de 2019, https://revistas.um.es/analesdoc/article/view/70321.
} 


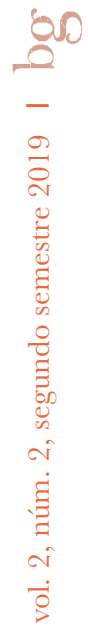

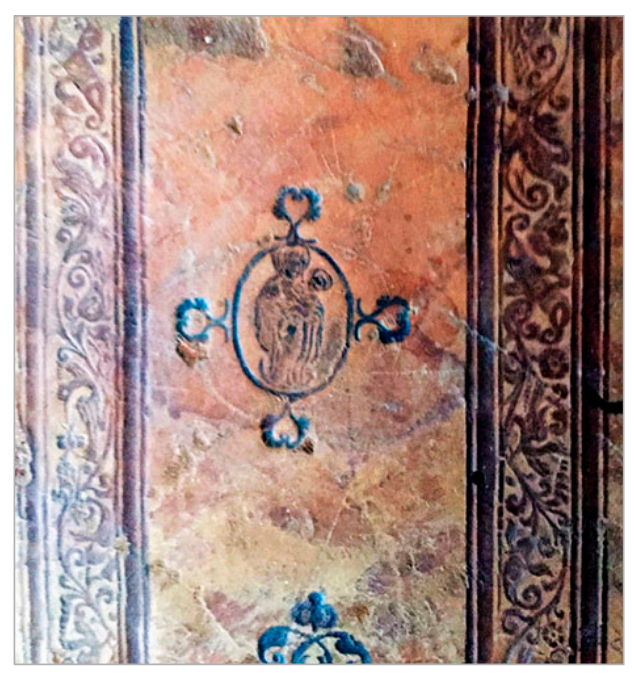

Figura 8. Detalle de la decoración de cubiertas. Fotografía del autor.

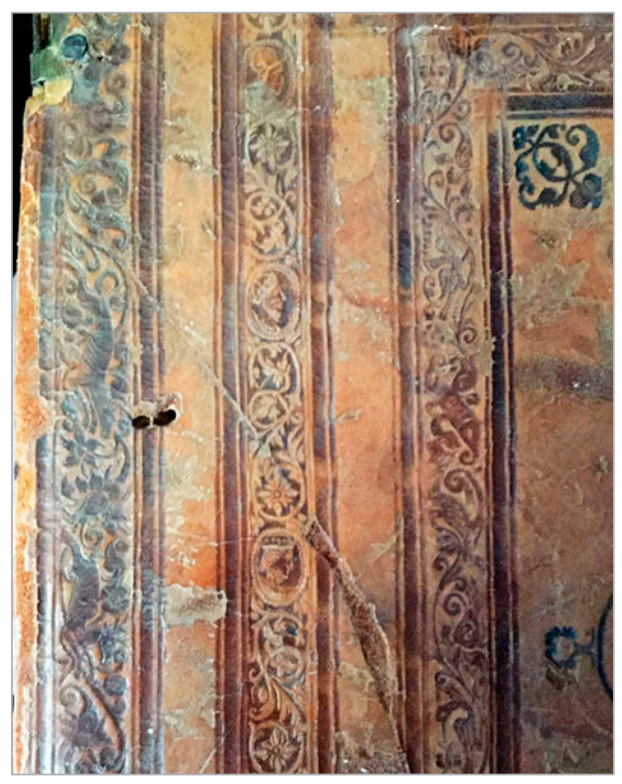

Figura 9. Detalle de la decoración de cubiertas. Fotografía del autor.

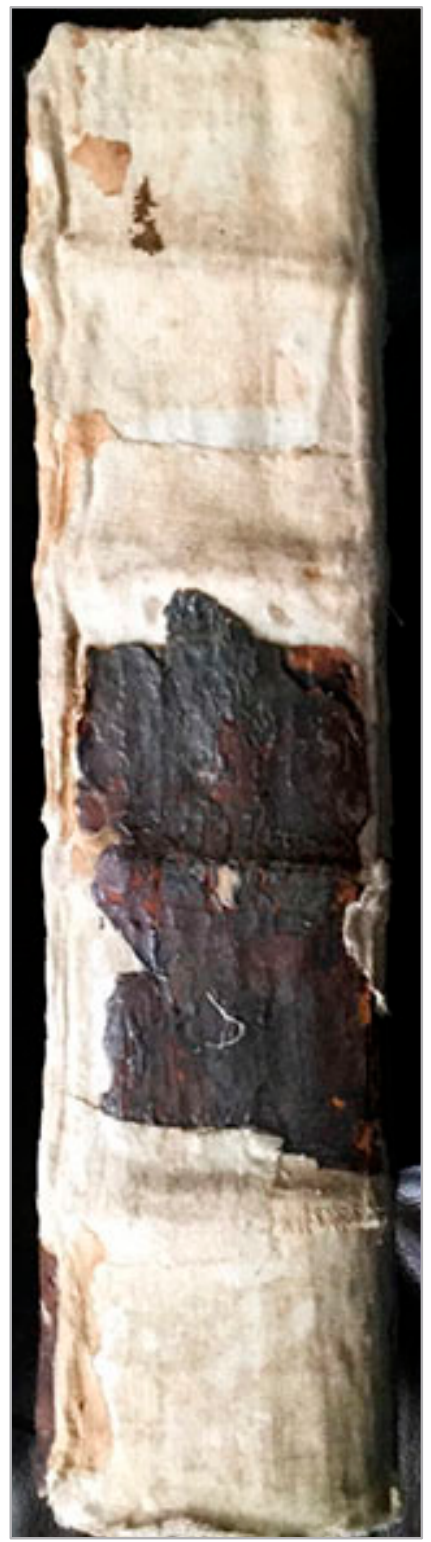

Figura 10. Lomo.

Fotografía del autor. 


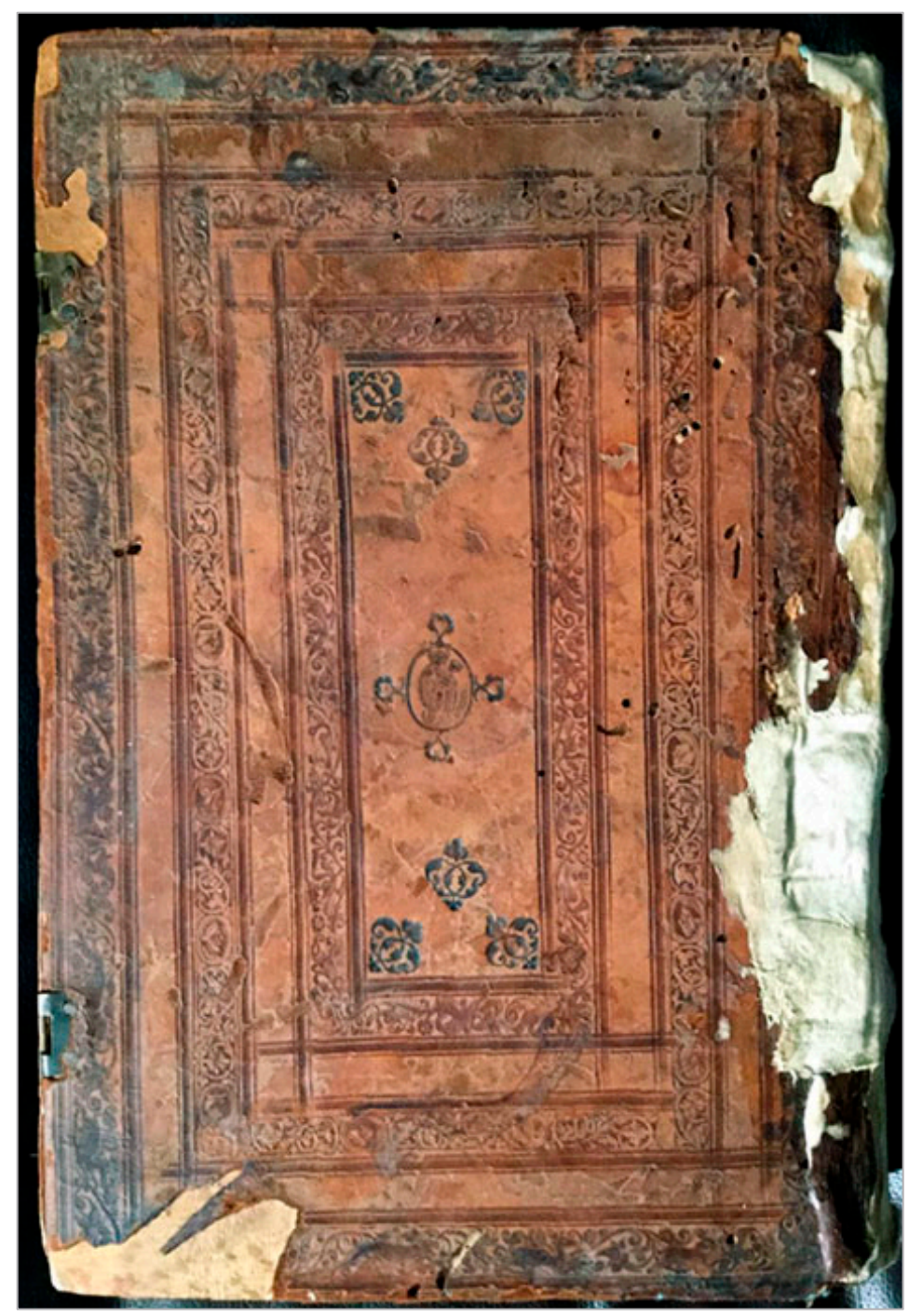

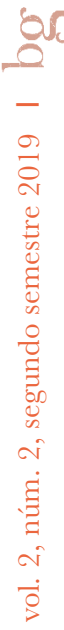

Figura 11. Cubierta posterior del libro de Ribera.

Fotografía del autor. 


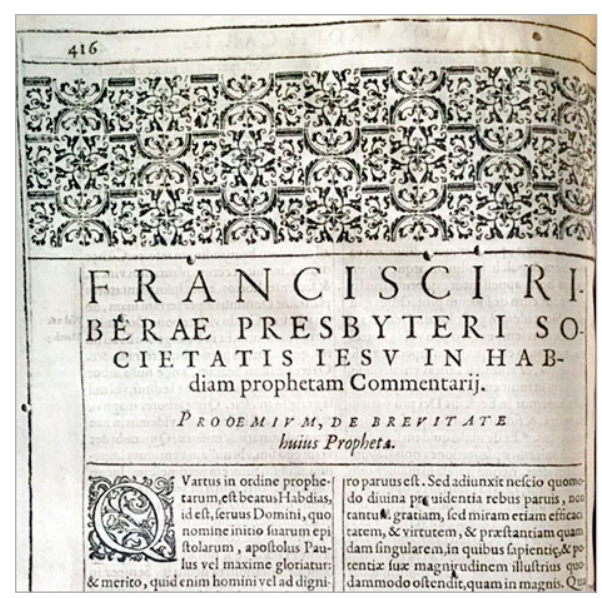

Figura 12. Orla tipográfica y capitular. Fotografía del autor.

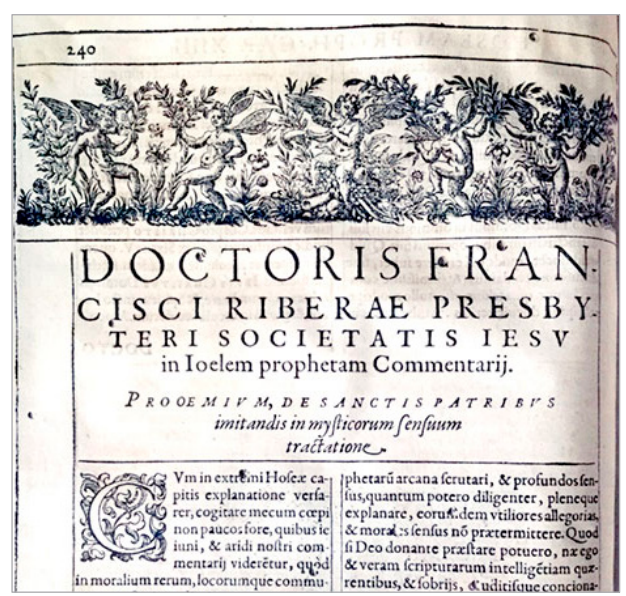

Figura 13. Orla tipográfica y capitular. Fotografía del autor.

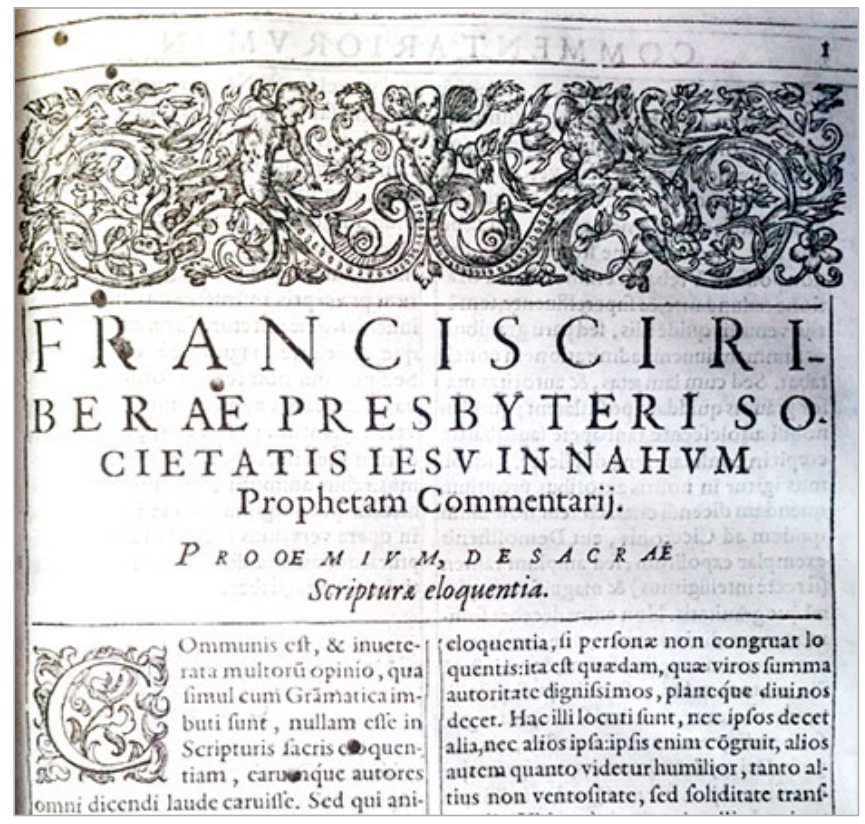

Figura 14. Orla tipográfica y capitular.

Fotografía del autor. 


\section{El contexto y la importancia de la obra de Ribera}

Al describir el grueso de los impresos inventariados en los registros de los años 1583-1584 y 1605 de navíos de las flotas españolas que iban hacia el Nuevo Mundo (sección de Contratación del Archivo General de Indias de Sevilla), Carlos Alberto González Sánchez encontró que -dentro de los rubros de teología y hagiografía - las obras de Francisco de Ribera fueron de las más enviadas a América. Dichos inventarios registran que se remitieron 24 ejemplares de la Vida de Santa Teresa de Jesús publicada en 1602, 25 ejemplares de su Theologi in sacram b. Ioahannis Apostoli et Evangelistae Apocalypsin Comentarii y tres de In librum duodecim Prophetarum comentarii. ${ }^{33}$

Sin embargo, el libro de los comentarios a los 12 profetas fue más popular de lo que indican dichos registros. En la colección de Obras Antiguas, Raras, del Fondo Reservado de la Biblioteca Nacional de México se encuentran dos ejemplares de la edición de 1587: uno con marca de fuego del convento de carmelitas de San Ángel y otro con la del convento de San Agustín, ${ }^{34}$ mientras que en el catálogo de la Biblioteca Pública de Jalisco se registran tres ejemplares de la misma edición: uno proveniente de la biblioteca del Seminario Conciliar Tridentino de San José de Guadalajara (originalmente perteneciente al obispo Juan Ruiz Cruz de Cabañas y Crespo), otro del convento de San Francisco de Guadalajara y el último sin marcas de procedencia específica. ${ }^{35}$ Así que, al parecer, esta obra fue una referencia teológica popular entre el clero secular y diversas órdenes religiosas en México. ${ }^{36}$

${ }_{33}$ Carlos Alberto González Sánchez, New World Literacy: Writing and Culture Across the Atlantic, 1500-1700 (Maryland: Bucknell University Press, 2011), 162-163, 170.

34 Véanse las fichas correspondientes bajo la clasificación RFO 224.907 RIB.i 1587 en Nautilo, catálogo de la Biblioteca y Hemeroteca Nacionales de México, acceso el 20 de mayo de 2019, http://catalogo.iib.unam.mx/F/UYM61PFSDEC34V231LAL4YQRSH2V GAUG89AS2SC835NGVTTB9K-01321?func=full-set-set\&set_number=008967\&set_en try $=000084 \& f o r m a t=999$. En el mismo aparecen dos ejemplares de la edición de 1599 con marcas de fuego del Oratorio de San Felipe Neri y de la librería del convento de San Diego, además de dos ejemplares de la edición de 1611 con los comentarios del jesuita Richard Gibbons y marcas de fuego del Colegio de Santos, del convento de la Merced.

${ }_{35}$ Clasificados bajo el número de sistema 000024539, en el catálogo general de la Biblioteca Pública del estado de Jalisco Juan José Arreola, acceso el 20 de mayo de 2019, http://www.bpej.udg.mx/catalogo.

${ }^{36}$ A través del Banco de datos de Fondos Bibliográficos Antiguos de México, de la institución Apoyo al Desarrollo de Archivos y Bibliotecas de México, A. C. (Adabi), se detectaron además otros ejemplares del mismo libro en diferentes ediciones y en distintos repositorios: tres en la Biblioteca Palafoxiana de Puebla, uno de la edición de 1587 y con exli- 
Para comprender la importancia de la obra de Ribera debemos recordar que se enmarca en el contexto de las polémicas generadas por la declaración del Concilio de Trento en su cuarta sesión del 8 de abril de 1546, que declaraba la versión latina, Vulgata, de la Biblia como la versión canónica de la Iglesia católica, ${ }^{37}$ en respuesta a la postura protestante de rechazar dicha versión frente a los originales en hebreo y griego. Tal declaración también tuvo como consecuencia indirecta que, además de promover los estudios escriturarios, algunos teólogos (entre ellos Ribera) se dedicaran a formular exégesis e interpretaciones bíblicas menos "hebraizantes" y bajo "el influjo rabínico en la interpretación bíblica como un aspecto grave de la judaización del cristianismo", por ejemplo las que en su momento promovieron fray Luis de León y Benito Arias Montano. ${ }^{38}$

Es importante recalcar el hecho de que la publicación del libro de Ribera en 1587 debe analizarse en el contexto de las discusiones teológicas y filológicas sobre la exégesis de los textos bíblicos, desatadas a partir del concilio tridentino. Debemos recordar que la controversia entre hebraístas y defensores del texto de la Vulgata tenía que ver, en lo esencial, con la forma de interpretar los textos bíblicos. Los hebraístas optaban por una interpretación más literal de las Escrituras a partir de los textos en sus lenguas originales, expresando diferencias con aquellos comentaristas que se inclinaban más por el uso de la Vulgata y una interpretación más apoyada en los cuatro sentidos tradicionales de la Sagrada Escritura, propuestos originalmente por san Juan Casiano (360435 d. C.): literal (o histórico), alegórico, tropológico (o moral) y anagógico

bris manuscrito: "Col. de Sn. Ildefonso. Puebla" (núm. de localización 5324), otro de 1593 con pie de imprenta "Coloniae Agripinae: In Officina Birckmannica" (núm. de localización 5596) y otro de 1612 con pie de imprenta "Oficina Typographica Baltazaris Belleri" (núm. de localización 5597). Estos dos últimos llevan el exlibris manuscrito "De la Compañía de Jesús de Puebla". Dos ejemplares más de la edición original de 1587 se localizan en la Biblioteca Armando Olivares Carrillo de la Universidad de Guanajuato, Fondo Conventos, con la marca de fuego del Convento del Carmen de Celaya, Gto. (núm. de localización 5237), y otro en la Biblioteca Francisco de Burgoa, Colección Antigua, de la Universidad Autónoma Benito Juárez de Oaxaca, con marca de fuego del Convento de Santo Domingo de Oaxaca (núm. de localización 603), acceso el 20 de mayo de 2019, http://www. adabi.org.mx/libro-antiguo.html?id=19.

${ }^{37}$ Iglesia católica, El sacrosanto y ecuménico Concilio de Trento, 6a. ed., trad. de Ignacio López de Ayala (Madrid: Imprenta que fue de García, 1819), 33.

${ }^{38}$ Francisco Javier Perea Siller, "Exégesis bíblica y confrontación racial: los comentarios sobre Abdías 20 de Francisco de Ribera y Luis de León", eHumanista / Conversos 2 (2014): 142-155, acceso el 20 de mayo de 2019, http://www.ehumanista.ucsb.edu/sites/secure.Isit. ucsb.edu.span.d7_eh/files/sitefiles/conversos/volume2/10ehumanconv.PereaSiller.pdf. 
(o místico). De hecho, en sus comentarios a los 12 profetas menores Ribera desarrolla, en todos los capítulos dedicados a estos, un resumen del argumento seguido del texto correspondiente de la Vulgata y luego añade la interpretación histórica, la alegórica y la tropológica, según requiera el texto.

Por otra parte, recuérdese que la publicación del texto de Ribera en 1587 fue precedida por una larga cadena de discusiones sobre estos temas de exegética escrituraria. Al menos desde 1566 estas controversias estaban vivas en Salamanca, a causa de la solicitud hecha a la Inquisición por el tipógrafo salmantino Gaspar de Portonares para expurgar e imprimir una versión de la llamada Biblia de Vatablo. Era una versión de la Vulgata con escolios y comentarios en ocasiones poco ortodoxos, que debía ser expurgada para su uso en instituciones católicas. Se encargó la labor a la Universidad de Salamanca, que formó comisiones encargadas para la tarea, no exenta de controversias, en las cuales participó fray Luis de León. Esta versión fue terminada en 1571, pero avivó las discusiones sobre la manera correcta de interpretar los textos de la Escritura.

Recordemos también que uno de los eventos más destacados de esos tiempos fue el proceso inquisitorial de 1571 contra fray Luis de León por su traducción literal de la versión hebrea del Cantar de los cantares, del cual salió exonerado en 1576. Estas controversias amainaron a finales del siglo XVI, pues como lo señala Leopoldo Juan García: "publicada la corrección clementina de la Vulgata ${ }^{39}$ en 1592, no era posible ya poner en duda que la venerable traducción declarada auténtica por el Concilio fuese susceptible de enmiendas, y por consiguiente que tenía pasajes no bien vertidos en las redacciones que corrían, hasta la indicada fecha cuando menos". 40

La enseñanza e interpretación de las Escrituras fue materia fundamental en las instituciones educativas jesuitas. En las Constituciones de la Sociedad de Jesús (parte IV, cap. 14, “De los libros que se han de leer") san Ignacio estableció que en las universidades jesuitas debían darse lecciones del Antiguo y del Nuevo Testamento, así como sobre la teología escolástica de santo Tomás. ${ }^{41}$ Además

39 Se refiere a la versión corregida del texto de la Vulgata Sixtina (1590), uno de cuyos editores fue el cardenal jesuita Roberto Belarmino y que fue promulgada por el papa Clemente VIII en 1592. Al contrario de otras ediciones previas de la Vulgata, esta edición no contenía variantes y pretendía ser "definitiva". Véase S. L. Greenslade (ed.), The Cambridge History of the Bible. The West from the Reformation to the Present Day, version digital (Londres: Cambridge University Press, 2004), 67-69.

${ }^{40}$ Leopoldo Juan García, Los estudios bíblicos en el Siglo de Oro de la universidad salmantina (Salamanca: Establecimiento Tipográfico de Calatrava, 1921), 50-54.

${ }^{41}$ Loyola, Obras completas, 543. 
debería haber profesores de griego y hebreo, con la intención de que, entre otros motivos, los estudiantes jesuitas fuesen capaces de defender la Vulgata. ${ }^{42}$

\section{Conclusiones}

Dentro de la historia cultural y el estudio de las mentalidades resulta fundamental el análisis de las bibliotecas y su relación con la cultura escrita. La revisión de los libros contenidos en cada repositorio nos permite tratar de reconstruir el contexto cultural e intelectual del que formaron parte. Al llevar a cabo la identificación de una obra e insertarla en un catálogo, la obra y su contenido -como lo señala Roger Chartier- deben ser analizados en función de la manera específica en que fueron formulados o producidos en su forma original, más que categorizarlos en función de remotas semejanzas con otros sistemas y formas codificadas que forman parte del repertorio de la cultura popular occidental, ${ }^{43}$ como en ocasiones ocurre cuando se trata de explicar la importancia de un texto de interpretación bíblica, escrito en tiempos ajenos a los nuestros.

A pesar de que el inventario de los ejemplares sobrevivientes de la biblioteca del Colegio de la Compañía de Pátzcuaro se encuentra incompleto (probablemente, con otras investigaciones, la nómina de obras se irá acrecentando en el futuro), el análisis de estos libros nos permite tener una idea de los contenidos y de la posible orientación ideológica del mismo.

De hecho, si comparamos el inventario sobreviviente del Colegio de Pátzcuaro con el de las bibliotecas de otros colegios jesuitas, se observa cierta uniformidad de contenidos. Por ejemplo, en el inventario de los libros del colegio jesuita de San Luis Potosí, descrito por Idalia García Aguilar, aparecen los textos de Juan Lorin (o Lorini) sobre los comentarios al libro de los Salmos, diversas obras del cardenal Roberto Belarmino y varios tomos de las Disputationes de Francisco Suárez, como también están en el inventario del Colegio de Pátzcuaro. ${ }^{44} \mathrm{Y}$ ello no es de extrañar. En su Fórmula del Instituto aprobada por Julio III, dentro de las Constituciones, san Ignacio había establecido que todos los que profesaban en la Compañía "son soldados de Dios que militan debajo de la fiel obediencia de nuestro santísimo señor el papa Paulo III y de los otros Romanos

\footnotetext{
42 Greenslade, The Cambridge History of the Bible, 214-215.

${ }^{43}$ Roger Chartier, "Review: Text, Symbols and Frenchness", The Journal of Modern History 57, núm. 4 (diciembre de 1985): 694.

${ }^{44}$ García Aguilar, "Entre el olvido y la supervivencia...", 48-105.
} 
pontífices sus sucesores", ${ }^{45}$ otorgándole al prepósito de la Compañía toda autoridad y poder para la buena administración, corrección y gobierno de la misma, incluyendo los estudios.

La uniformidad ideológica en la capacitación de este ejército era fundamental para asegurar la disciplina de sus miembros. De hecho, la orientación de la teología jesuita para reforzar la obediencia al papado no fue bien vista por la Corona española, tanto que "en agosto de 1768 las cátedras de la escuela jesuítica quedaron extinguidas en virtud de una nueva cédula real en la que se prohibía el empleo de los autores de dicha escuela" y "desaparecieron los textos de grandes teólogos jesuitas -Molina, Mariana, Belarmino, Vázquez, Busembaum-y dejaron de enseñarse las teorías populistas de Francisco Suárez" ${ }^{46}$ Recuérdese por ejemplo que, además de defender la primacía del papado, en 1613 Suárez publicó su Defensa de la fe católica y apostólica contra los errores de la secta anglicana, en la cual proponía que "ningún rey o monarca tuvo (según la ley ordinaria) inmediatamente de Dios o por institución divina el poder, sino mediante la institución y poder de los hombres". ${ }^{47}$

Esta animadversión hacia la orientación de los jesuitas en contra de la justificación de los derechos divinos absolutos de la Corona explica, en parte, la prohibición de ciertos de sus autores y la destrucción de varias obras pertenecientes a los colegios de la Compañía.

Para finalizar, no podemos sino recalcar la importancia que tiene el estudio de las bibliotecas de personajes o instituciones religiosas de la época colonial, pues representan una ventana invaluable para el estudio de las mentalidades y la ideología de cada época. De modo que -dentro de este estudio-cada libro, cada granito de arena, cuenta.

\section{Referencias}

Apoyo al Desarrollo de Archivos y Bibliotecas de México, A. C. (Adabi). Banco de datos de Fondos Bibliográficos Antiguos de México. Acceso el 20 de mayo de 2019. http://www.adabi.org.mx/libro-antiguo.html?id=19.

\footnotetext{
${ }^{45}$ Loyola, Obras completas, 436-437.

${ }^{46}$ García Aguilar, "Entre el olvido y la supervivencia...", 63.

47 José Manuel Gallegos Rocafull, El hombre y el mundo de los teólogos españoles de los siglos de oro (México: Editorial Stylo, 1946), 109. También consúltese este libro para una excelente exposición de conjunto sobre las principales corrientes teológicas españolas de los siglos XVI y XVII, expuestas por Báñez, Molina, Vitoria, Suárez y otros.
} 
Bayerische StaatsBibliothek digital de Munich. Acceso el 4 de julio de 2019. https://reader.digitale-sammlungen.de/de/fs1/object/display/bsb10 159415_00005.html.

https://books.google.com.ar/books?id=QwtEAAAAcAAJ\&printsec= frontcover\&hl=es\#v=onepage\&q\&f=false. https://books.google.com.mx/ books? $i d=d Q t E A A A A c A A J \& p$ rintse $c=$ frontcover\&hl=es\&source $=g$ bs_ ge_summary_r\&cad $=0 \# v=$ onepage $\& q \& f=f a l s e$.

Biblioteca y Hemeroteca Nacionales de México. Catálogo Nautilo. Acceso el 20 de mayo de 2019. http://catalogo.iib.unam.mx/F/UYM61PFSDEC34 V231 LAL4YQRSH2VGAUG89AS2SC835NGVTTB9K-01321? func=fu II-set-set\&set_number=008967\&set_entry=000084\&format=999.

Biblioteca Pública del estado de Jalisco Juan José Arreola. Catálogo general. Acceso el 20 de mayo de 2019. http://www.bpej.udg.mx/catalogo.

Bibliothèque Mazarine de París. Acceso el 4 de julio de 2019. https://www.bi bliotheque-mazarine.fr/en/catalogues.

Burrieza Sánchez, Javier. "Francisco de Ribera". En Diccionario biográfico español de la Real Academia de la Historia. Acceso el 20 de mayo de 2019. http://dbe.rah.es/biografias/20974/francisco-de-ribera.

Castañeda, Carmen, coordinadora, y Myrna Cortés, colaboradora. Del autor al lector. I. Historia del libro en México. México: CIESAS / Miguel Ángel Porrúa, 2002.

Catálogo Colectivo del Patrimonio Bibliográfico Español (CCPB). Acceso el 20 de mayo de 2019. http://ccpb_opac.mcu.es/cgi-brs/CCPB/abnetopac/ O9068/ID998723eb/NT2 y http://catalogos.mecd.es/CCPB/cgi-ccpb/ab netopac/O12242/ID1c1ef102/NT2.

Cavallo, Guglielmo y Roger Chartier, coordinadores. Historia de la lectura en el mundo occidental. Madrid: Taurus, 1998.

Chartier, Roger. "Review: Text, Symbols and Frenchness". The Journal of Modern History 57, núm. 4 (diciembre de 1985): 682-695.

Fernández, Justino. Pátzcuaro. Su situación, historia, características. Con un plano pictórico de la ciudad. México: Talleres de Impresión de Estampillas y Valores, 1936.

Fernández de Córdova, Francisco. "Sumaria relación de las bibliotecas de Michoacán". Historia Mexicana 3, núm. 1 (julio-septiembre de 1953). Acceso el 14 de mayo de 2019. https://historiamexicana.colmex.mx/index.php/ $\mathrm{RHM} /$ issue/view/48. 
Gallegos Rocafull, José Manuel. El hombre y el mundo de los teólogos españoles de los siglos de oro. México: Editorial Stylo, 1946.

García Aguilar, Idalia. "Entre el olvido y la supervivencia: los libros jesuitas del Colegio de San Luis Potosí". Revista de El Colegio de San Luis 6, núm. 11 (enero-junio de 2016): 48-105. Acceso el 20 de mayo de 2019. http://www.scielo.org.mx/scielo.php?script=sci_arttext\&pid=S1665-899 X2016000100048\&lng=es\&tlng=es.

García Aguilar, Idalia. "Imprenta y librerías jesuitas en Nueva España". En El libro en circulación en la América colonial. Producción, circuitos de distribución y conformación de bibliotecas en los siglos XVI al XVIII, 205-237. México: Quivira, 2014.

García Aguilar, Idalia. Secretos del estante: elementos para la descripción bibliográfica del libro antiguo. México: Universidad Nacional Autónoma de México, 2011. Acceso el 20 de mayo de 2019. https://www.academia. edu/4192764/Secretos_del_estante_elementos_para_la_descripci\%C 3\%B3n_del_libro_antiguo.

García Aguilar, Idalia y Pedro Rueda Ramírez, coordinadores. El libro en circulación en la América colonial. Producción, circuitos de distribución y conformación de bibliotecas en los siglos XVI al XVIII. México: Quivira, 2014.

Ginzburg, Carlo. Mitos, emblemas, indicios. Morfología e historia. Barcelona: Gedisa, 2008.

González Sánchez, Carlos Alberto. New World Literacy: Writing and Culture Across the Atlantic, 1500-1700. Maryland: Bucknell University Press, 2011.

Greenslade, S. L., editor. The Cambridge History of the Bible. The West from the Reformation to the Present Day. Versión digital. Londres: Cambridge University Press, 2004.

Iglesia católica. El sacrosanto y ecuménico Concilio de Trento. 6a. ed. Traducción de Ignacio López de Ayala. Madrid: Imprenta que fue de García, 1819.

Juan García, Leopoldo. Los estudios bíblicos en el Siglo de Oro de la universidad salmantina. Salamanca: Establecimiento Tipográfico de Calatrava, 1921.

Lorenzo Pinar, Francisco Javier. "Contratos de impresión de libros con los tipógrafos extranjeros en Salamanca en el siglo XVI". Documenta e Instrumenta 16 (2018). Acceso el 14 de mayo de 2019. DOI: http://dx.doi.org/10.5209/ rev_DOCU.2018.v16.60230.

Loyola, Ignacio de. Obras completas. 3a. ed. revisada. Madrid: Biblioteca de Autores Cristianos, 1977. 
Miguélez González, Elvira Julieta. "El influjo renacentista en las encuadernaciones de la Biblioteca Histórica de la Universidad de Salamanca". Anales de Documentación 12 (2009). Acceso el 4 de julio de 2019. https://revistas. um.es/analesdoc/article/view/70321.

Palau y Dulcet, Antonio. Manual del librero hispano-americano. Tomo sexto. P-S. Barcelona: Librería Antiquaria, 1927.

Perea Siller, Francisco Javier. "Exégesis bíblica y confrontación racial: los comentarios sobre Abdías 20 de Francisco de Ribera y Luis de León". eHumanista / Conversos 2 (2014). Acceso el 20 de mayo de 2019. http://www. ehumanista.ucsb.edu/sites/secure.Isit.ucsb.edu.span.d7_eh/files/sitefiles/ conversos/volume2/10ehumanconv.PereaSiller.pdf.

Ribera, Francisco de. Librum duodecim Prophetarum commentarii. Salamanca: Guillermo Foquel, 1537. Acceso el 4 de julio de 2019. https://babel.hathi trust.org/cgi/pt?id=ucm.5316851323\&view=1 up\&seq $=7$.

https://books.google.com.mx/books?id=PjNoN0MqkJIC\&printsec=front cover\&sour ce=gbs_ge_summary_r\&cad=0\#v=onepage\&q\&f=false.

Schenone, Héctor H. Iconografía del arte colonial. Los santos. Vol. I. Buenos Aires: Fundación Tarea, 1992.

Silva Mandujano, Gabriel. "Colegio de la Compañía de Jesús de Pátzcuaro". En Nuestros libros. Encanto de lo antiguo. Coordinación de Juan García Tapia. Morelia: Universidad Michoacana de San Nicolás de Hidalgo, 2002.

Tello, Antonio, fray. Crónica Miscelánea de la Sancta Provincia de Xalisco. Tomo III. Introducción de José Cornejo Franco. Guadalajara: Editorial Font, 1942.

Tello, Antonio, fray. Libro segundo de la Crónica Miscelánea en que se trata de la conquista espiritual y temporal de la Santa Provincia de Xalisco. Introducción de José López Portillo y Rojas. Guadalajara: Imprenta de La República Literaria de Ciro I. de Guevara, 1891.

Thüringer Universitäts- und Landesbibliothek (ThULB). Acceso el 4 de julio de 2019. https://kataloge.thulb.uni-jena.de.

Vergara Ciordia, Javier. "El proceso de expropiación de la biblioteca de los jesuitas en Pamplona (1767-1774)". Revista de Historia Moderna, núm. 26 (2008). Acceso el 14 de mayo de 2019. Dol: https://doi.org/10.14198/ RHM2008.26.11.

Zozaya-Montes, Leonor. "Algunas aclaraciones sobre Guillermo Foquel, un impresor del siglo XVI". Torre de los Lujanes 43 (2001). Acceso el 14 de mayo de 2019. http://digital.csic.es/handle/10261/29822. 